\title{
PENYULUHAN CUCI TANGAN PAKAI SABUN DI SDN 128 PEKANBARU KELURAHAN RANTAU PANJANG PEKANBARU
}

\author{
M. Fajar Anugerah ${ }^{1)}$ Husnah $^{2)}$ Wita Yulianti $^{3)}$ Siti Juariah ${ }^{4)}$ \\ 1)Prodi Ilmu Pemerintahan, Fakultas Ilmu Sosial dan Ilmu Politik, Universitas Abdurrab \\ ${ }^{2}$ Prodi Teknik Sipil, Fakultas Teknik, Universitas Abdurrab \\ ${ }^{3)}$ Prodi Teknik Informatika, Fakultas Teknik, Universitas Abdurrab \\ 4)Program Studi Analis Kesehatan, Fakultas Kedokteran dan Ilmu Kesehatan, \\ Universitas Abdurrab \\ Jl. Riau Ujung No. 73, Kota Pekanbaru, 28292, Indonesia \\ email: fajar.anugerah@univrab.ac.id
}

\begin{abstract}
ABSTRAK
Permasalahan perilaku kesehatan pada anak usia sekolah berkaitan dengan kebersihan perorangan dan lingkungannya. Salah satu pemasalahan kesehatan yaitu kurangnya kesadaran terhadap cuci tangan pakai sabun. Tujuan penelitian ini adalah untuk mengetahui pengetahuan siswa siswi sdn 128 Rumbai Pekanbaru. Jenis penilitian ini adalah kualitatif penelitian yang bermaksud memahami fenomena tentang apa yang dialami oleh subjek penelitian misalnnya perilaku, presepsi, motivasi, cara deskripsi dalam bentuk kata-kata dan bahasa, pada suatu konteks khusus yang alamiah dan dengan memanfaatkan berbagai metode alamiah. Sampel penelitian iualah siswa SD Negri 128 rumbai Pekanbaru. Hasil penelitian menunjukkan bahwa sebagian besar responden tidak memiliki pengetahuan yang baik bagaimana cara mencuci tangan yang baik dan benar.
\end{abstract}

Kata kunci : Penyuluhan, cuci tangan pakai sabun, metode simulasi

\begin{abstract}
Health behavior problems in school-age children are related to personal hygiene and the environment. One health problem is the lack of awareness of washing hands with soap. The purpose of this study was to determine the knowledge of students at 128 Rumbai Pekanbaru. This type of research is qualitative research that intends to understand the phenomena about what is experienced by research subjects such as behavior, perception, motivation, ways of description in the form of words and language, in a special natural context and by utilizing various natural methods. The research sample was elementary school students in 128 tassel Pekanbaru. The results showed that the majority of respondents did not have good knowledge on how to wash hands properly.
\end{abstract}

Key words: Counseling, wash your hands with soap, simulation method 


\section{PENDAHULUAN}

Cuci tangan yang baik dan benar adalah menggunakan air bersih yang mengalir dan memakai sabun. Kegiatan cuci tangan pakai sabun merupakan salah satu indikator PHBS di sekolah. Peringaan cuci tangan pakai sabun 2010 mengangkat sub tema "Cuci Tangan Pakai Sabun". Perilaku sederhan berdampak luar biasa (Kemenkes RI, 2010). Permasalahan perilaku kesehatan pada anak usia sekolah biasanya berkaitan dengan kebersihan perorangan dan lingkungannya. Salah satu permasalahan karna kurangnya kesadaran terhadap cuci tangan pakai sabun adalah masalah Diare. Di duia sebanyak 6 juta anak meninggal setiap tahunnya karena diare, sebagian kematian tersebut terjadi di negara berkembang. Di perkirakan lebih dari 10 juta anak berusia kurang dari 5 tahun meninggal setiap tahunnya, sekitar 20\% meninggal karena infeksi diare (Kemenkes RI, 2011).

Persepsi dan perilaku terhadap kebiasaan mencuci tangan menemukan bahwa sabun telah sampai ke hampir setiap rumah di indonesia, namun sekitar 3\% yang menggunakan sabun untuk cuci tangan, untuk didesa angkanya bisa lebih rendah lagi. Mencuci tangan pakai sabun dapat menurunkan resiko diare hingga 50\% ( WHO, 2011).

Anak usia sekolah merupakan kelompok usia yang kritis, karena pada usia tersebut seorang anak rentan terhadap masalah kesehatan. Selain rentan terhadap masalah kesehatan, anak usia sekolah juga berada pada kondisi yang sangat peka terhadap stimulus sehingga mudah dibimbing, diarahkan, dan ditanamkan kebiasaan-kebiasaan yang baik, termasuk kebiasaan berperilaku hidup bersih dan sehat. Pada umumnya, anak-anak seusia ini juga memiliki sifat selalu ingin menyampaikan apa yang diterima dan diketahuinya dari orang lain (Nadia, 2012).

Menurut Djauzi (2008), mencuci tangan merupakan salah satu cara untuk menghilangkan kuman dan untuk menghindari penularan penyakit. Di sekolah, anak tidak hanya belajar, tetapi banyak kegiatan lain seperti bermain, bersentuhan, ataupun bertukar barang-barang dengan teman-teman. Kuman yang terdapat di alat tulis, buku, dan benda lain akan mudah berpindah dari tangan satu anak ke anak lainnya, sehingga penyakit akan mudah menular. Jadi, mencuci tangan harus dilatih sejak dini pada anak agar memiliki kebiasaan mencuci tangan, sehingga anak terhindar dari penyakit.

Sekolah Dasar Negeri 128 Kecamatan Rumbai Kelurahan Rantau Panjang Pekanbaru merupakan institusi pendidikan pada anak yang berusia dari 6-13 tahun. Sekolah Dasar Negeri 128 Kecamatan Rumbai terletak di kelurahan Rantau Panjang dan berada dipinggir jalan yang merupakan daerah perdesaan yang cukup jauh dari kota. Berdasarkan wawancara yang dilakukang dengan bapak kepala sekolah Bapak Paisal Rusdianto S.pd Sd beliau mengatakan masih kurangnya pendidikan kesehatan tentang mencuci tangan dan belum ada penyuluhan kesehatab tentang pentingnya mencuci tangan menggunakan sabun dari petugas kesehatan.

Berdasarkan data yang di peroleh, maka kami peserta kukerta tertarik untuk melakukan penyuluhan dengan judul " Pengetahuan siswa siswiterhadap pentingnya penyuluhan cuci tangan pakai sabun di SDN 128 Kecamatan Rumbai Kelurahan Rantau Panjang Pekanbaru.

\section{TINJAUAN PUSTAKA}

A. Definisi Cuci Tangan Pakai Sabun (CPTS)

Cuci Tangan Pakai Sabun (CPTS) merupakan salah satu tindakan sanitasi dengan membersihkan tangan dan jari jemari menggunakan air dan sabun oleh manusia untuk menjadi bersih dan memutuskan rantai kuman. Cuci tangan pakai sabun juga dikenal 
sebagai salah satu upaya pencegahan penyakit . hal ini dilakukan karena tangan seringkali menjadi agen pembawa kuman dan menyebabkan patogen patogen berpindah dari satu orang ke orang lain, baik dengan kontak langsung ataupun tidak lansgung (Kemenkes, 2014).

Fungsi cuci tangan menurut Proverawati dan Rahmawati (2012) dan Sukoharjo (2011), fungsi dari cuci tangan diantaranya yaitu :

1. Cuci tangan dapat berfungsi untuk menghilangkan atau mengurangi mikrorganisme yng menempel ditangan.

2. Untuk mencegah penyakit misalnya seperti Diare, Kolera, ISPA, Cacingan, Flu Dan Hepatitis

3. Menjadikan tangan bersih dari kuman dan terhidar dari penyakit

4. Melindungi kesehatan keluarga

5. Merupakan upaya sederhana, terjangkau untuk mencapai sehat

6. Mendidik anggota keluarga untuk berperilaku besih

Prosedur yang baik dan benar menurut WHO enam langkah cuci tangan yang benar adalah :

1. Bersihkan tangan dengan air dan sabun lalu gosokkan kedua telapak tangan.

2. Gosok bagian punggung tangan dan sela-sela jari, lakukan pada kedua tangan

3. Gosok kedua telapak tangan dan sela-sela jari

4. Gosok punggungtangan dua tangan dengan posisi saling mengunci dan interlocking

5. Gosok ibu jari dengan arah diputar oleh tangan yang berlawanan ulangi langkah yang sama untuk ibu jari selanjutnya

6. Gosok ujung kuku tangan pada lengan yang berlawanan lalu ulangi untuk kuku tangan satunya. Terakhir bilas dengan air lalu tutu kerang memakai siku atau menggunakan siku.

B. Alat Yang Di Butuhkan Dalam Penyuluhan CPTS

1. Air bersih yang mengalir

2. Sabun atau hand sanitizer

\section{METODE PELAKSANAAN}

Metode pelaksanaan dalam kegiatan pengabdian kepada masyarakat ini adalah dengan menggunakan metode ceramah atau sosialisasi dan diakhir dengan melakukan praktek mencuci tangan pakai sabun. Pengabdian dilakukan di SDN 128 Kecamatan Rumbai Kelurahan Rantau Panjang Pekabaru pada tanggal 25 Juli 2019. Metode yang digunakan dalam kegiatan pengabdian kepada masyarakat in adalah dengan melakukan observasi ke SDN 128 Pekanbaru untuk melihat sejauh mana pentingnya penyuluhan cuci tangan ini kepada siswa karena memang belum ada kegiatan serupa di lokasi pengabdian ini.

Partisipasi mitra dalam kegiatan pengabdian kepada masyarakat ini yaitu seluruh warga sekolah SDN 128 Pekanbaru bersama dengan mahasiswa Kukerta Universtas Abdurrab Pekanbaru. Evaluasi pelaksanaan kegiatan pengabdian kepada masyarakat ini dilakukan dengan memberikan pengarahan tentang hidup sehat yang dimulai dari kegiatan mencuci tangan yang biasa dilakukan dari rumah dan setiap kegiatan di sekolah. Keberhasilan kegiatan pengabdian ini diukur dari antusias para siswa yang mengikuti kegiatan, adanya respon positif dari kepala sekolah dan juga keaktifan siswa siswi SDN 128 Pekanbaru untuk mempraktekan kegiatan cuci tangan pakai sabun dan setelah memberikan materi dan arahan kepada siswa-siswi tersebut demi mengetahui sejauh 
mana siswa-siswi tersebut memahami tentang materi yang sudah dibahas, mahasiswa/I yang memberikan materi kepada siswa-siswi tersebut mengajak untuk melakukan beberapa games yang mana tujuan dari games tersebut adalah untuk megetahui sejauh mana siswa-siswi tesebut memahami tentang materi-materi yang sudah diberikan oleh pemateri.

\section{HASIL DAN PEMBAHASAN}

Dalam undang-undang nomor 23 tahun 1992 tentang kesehatan ditetapkan bahwa kesehatan adalah keadaan sejahtera dari badan, jiwa dan sosial yang memungkinkan setiap orang hidup produktif secara sosial dan ekonomi. Dari kegiatan yang kami lakukan kami memilih untuk melakukan penyuluhan PHBS yaitu 6 langkah cuci tangan yang baikdan benar bagi siswa-siswi karna sangat berguna bagi mereka yang masih belum tau dan paham bahwa mencuci tangan sangat bermanfaat bagi kesehatan. Kegiatan penyuluhan ini merupakan salah satu kegiatan program kerja kelompok 20 di kelurahan rantau panjang kecamatan rumbai. Kegiatan ini dilaksanakan SDN 128 Kecamatan Rumbai Kelurahan Rantau Panjang Pekanbaru tepatnya di RT 02 RW 01 kelurahan rantau panjang. Subjek dari kegiatan yaitu siswa-siswi kelas 1 yang terdiri dari tiga kelas yaitu kelas a, b, dan kelas c yang total keseluruhan kelas berjumlah 85 orang.

Saat melakukan kegiatan 6 langkah cuci tangan yang baik dan benar anak-anak sangat antusias dalam kegiatan ini. Mereka mengikuti setiap langkah-langkah cuci tangan yang baik dan benar, sampai saat disuruh kedepan mereka semua mengangkat tangan untuk maju kedepan mempraktekan 6 langkah cuci tangan yang benar didepan sesuai yang sudah diajarkan oleh kami peserta kukerta kelompok 20, mereka dapat mengikuti kami karna metode yang kami ajarkan adalah belajar sambil bermain serta diikuti dengan gerakan dan musik sebagai penyemangat kegiatan penyuluhan yang kami lakukan agar siswa-siswi SDN 128 itu tidak merasakan bosan melakukan kegiatan penyuluhan tersebut. Bermain yang kami maksud disini acara tambahan yang kami selingi di selasela acara kegiatan penyuluhan dengan gerakan yang lucu dan musik yang menarik perhatian anak-anak tersebut, sehingga mereka semua sangat menyukai dan dapat mengikuti acara kegiatan ini dengan baik dan kami harapkan bisa menerapkannya dalam kehidupan sehari-hari agar menjauhkan dan menghindari diri mereka untuk terserang penyakit seperti sakit perut karena diare, dan lain sebagainya.

Dibawah ini terdapat dokumentasi saat kami kelompok 20 melaksanakan kegiatan penyuluhan yang dilakukakan pada siswa-siswi kelas 1 di SDN 128 Kecamatan Rumbai Kelurahan Rantau Panjang Pekanbaru. 


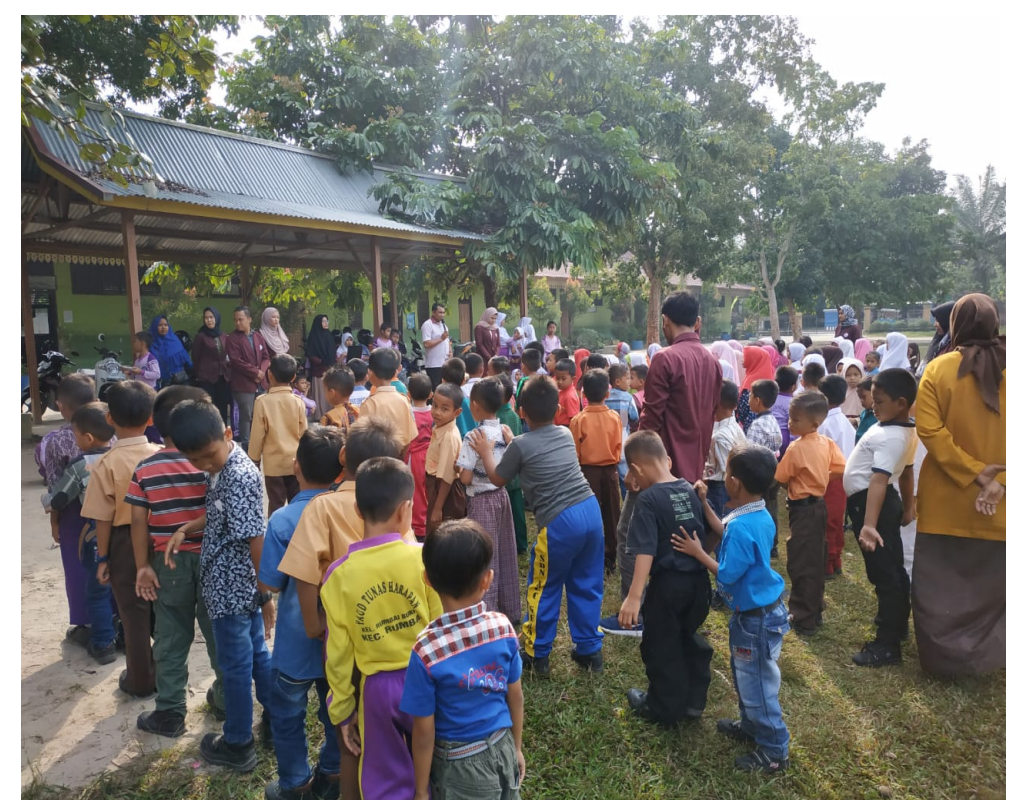

Gambar 1. Kata Sambutan Dari Kepala Sekolah SDN 128 Pekanbaru

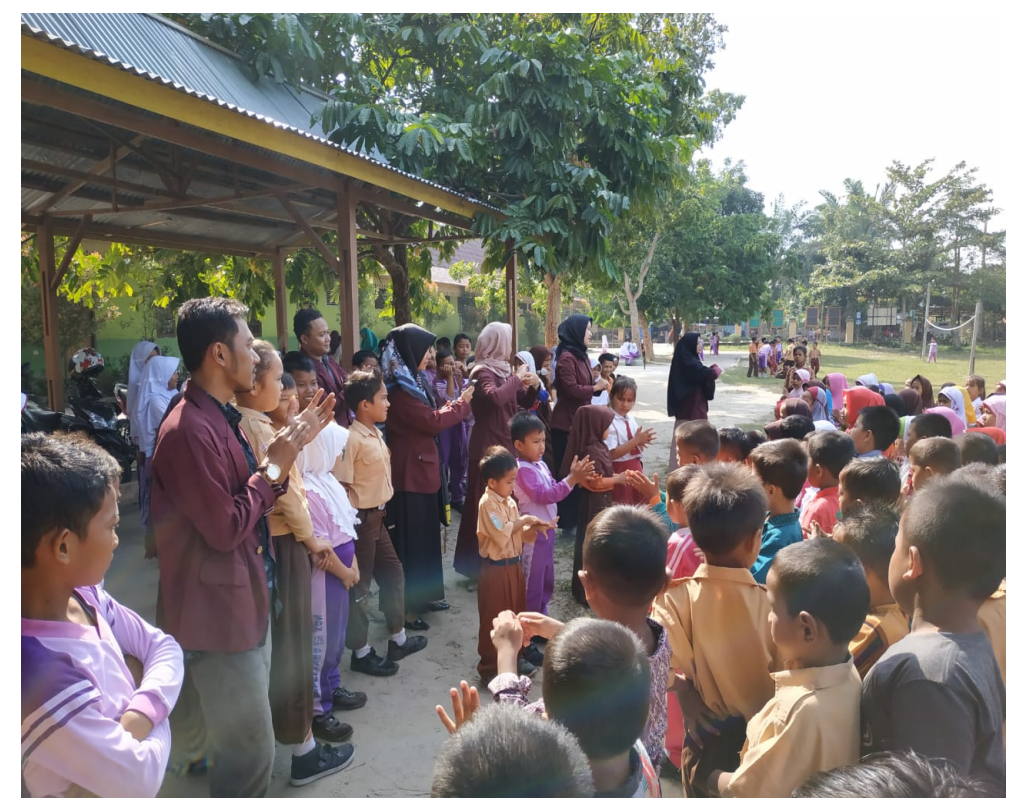

Gambar 2. Memperagakan 6 Langkah Cuci Tangan Sambil Senam Santai 


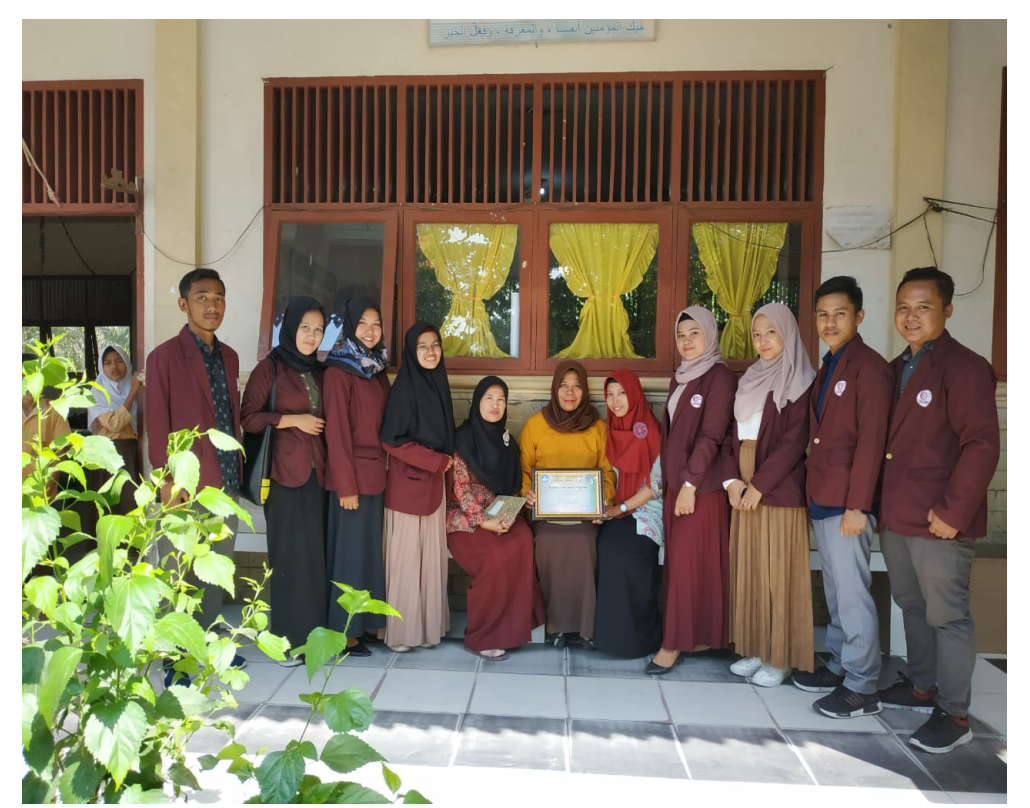

Gambar 3. Foto Bersama Perwakilan Guru SDN 128 Pekanbaru

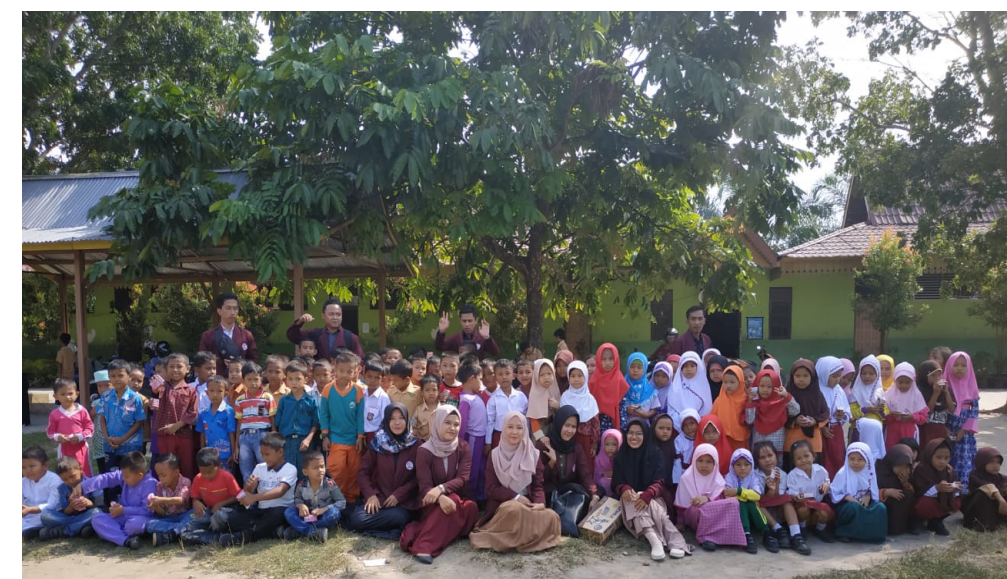

Gambar 4. Foto Bersama Dengan Siswa/i SDN 128 Pekanbaru

\section{KESIMPULAN}

Secara keseluruhan kegiatan penyuluhan PHBS berjalan dengan lancar. Jika ada kegiatan penyuluhan kesehatan seperti ini bisa dilakukan lebih baik lagi dan mempersiapkan segala bentuk dari kegiatan penyuluhan PHBS ini yang sangat penting dan bermanfaat bagi kesehatan dan diharapkan dengan adanya kegiatan seperti ini diharapkan kepada sekolah dan seluruh orang tua murid untuk dapat lebih mengajarkan kepada anak-anak mereka untuk menjaga kebersihan tangan agar anak-anak dapat terhindar dari segala macam penyakit dan pentingnya menjaga kebersihan lingkungan sekitar agar nyaman dan bersih. Terimakasih kepada bapak M Fajar Anugerah S.IP., M.Si selaku dosen pembimbing lapangan, kepada kepala sekolah SDN 128 kecamatan rumbai kelurahan rantau panjang pekanbaru yakni Bapak Paisal Rusdianto S.Pd, guru-guru dan seluruh staff SDN 128 kecamatan rumbai kelurahan rantau panjang yang telah mengizinkan kami dan mendukung kami dalam kegiatan penyuluhan sehingga kegiatan ini berjalan dengan baik. 


\section{DAFTAR PUSTAKA}

[1]. Djauzi, S. 2008. Raih Kembali Kesehatan Mencegah Berbagai Penyakit Hidup Sehat Untuk Keluarga. Jakarta: Kompas.

[2]. Kementerian Kesehatan RI. Jakarta. Peraturan Menteri Kesehatan Republik Indonesia Nomor 3 tahun 2014 tentang Sanitasi Total Berbasis Masyarakat (STBM); 2010

[3]. Kementerian Kesehatan RI. Jakarta. Perilaku Mencuci Tangan Pakai Sabun di Indonesia; 2014

[4]. Kementerian Kesehatan RI. Jakarta: Cuci Tangan Pakai Sabun (CTPS), Perilaku Sederhana yang Berdampak Luas Biasa; 2011 http://depkes.go.id/index.php/berita/pressrelease/2086.html [Accessed Oktober 2012]

[5]. Nadia, (2012). Hubungan pelaksanan program usaha kesehatan sekolah terhadap perilaku hidup bersih dan sehat pada siswa sdn 13 seberang padang utara tahun 2012. Universitas Andalas : Padang.

[6]. Proverawati, A. dan Rahmawati, E. Perlaku Hidup Bersih dan Sehat. Yogyakarta: Nuha Medika; 2012 